\title{
22
}

\section{Decision support in marketing}

\author{
Zita Zoltay Paprika \\ Budapest University of Economic Sciences \\ Budapest V. Veres Pálné st. 36. \\ H-1053. HUNGARY \\ Telephone: +3611183 037, facsimile: +3611172 959, \\ e-mail: paprika@mercur.bke.hu
}

\begin{abstract}
This paper takes the example of one of the most important Hungarian banks to show the requirements that a marketing information system must meet under the current Hungarian economic conditions to support the decision making implementing the marketing strategy in the increasing market competition.
\end{abstract}

Keywords
Decision support, marketing, data base marketing, computer implementation.

\section{INTRODUCTION}

At present data base marketing is the magic word in the international technical literature in relation to which views have been published that by the end of the millennium, according to more than $85 \%$ of the American firms, its application will be indispensable to remain competitive. These assumptions involve the obvious business consideration that costly mass marketing should be replaced with data base marketing which also allows for target marketing and thus marketing expenses may actually be targeted at customers who are worth it.

Without arguing with the adequacy of the above logic, it should be supplemented at several points. The majority of marketing decisions affect areas outside the firm, primarily the market and the participants in the market, consumers and competitors. However, the data base of a firm contains very little information about them especially if data are collected in relation to transactions. For example, it is absolutely sure that data base marketing can give no information at all about the satisfaction of customers. This is why a lot of information about consumers and competitors must be collected in different forms and from different sources and it must be classified according to the requirements of the given firm.

A marketing information system must reflect consumer orientation, competitor orientation and the service management concepts in its contents as well. In general the acceptance of the information system within a firm primarily depends on whether it is capable of meeting the information requirements. Very often decision makers are reluctant to state 
their exact requirements and then the developers of the system have to try to simulate the possible requirements. This is an extremely difficult task in a turbulent business atmosphere which requires frequent strategic adjustments from the players of the economy. Briefly, in such cases a solution should be found according to which the newly developed information system should be able to support basic decision making situations assuming more than one strategies.

The decision supporting nature of a marketing information system should not only be obvious in its contents but also in the structure in which information is stored and presented which should directly assist the decision making process. The classification of information according to subjects and inquiry options based on various marketing orientation may make the system suitable to support more complex, so called ill-structured decision making tasks too.

\section{PRECEDENTS TO THE ASSIGNMENT}

I took part in the development of the marketing information system, which is the subject of this analysis, as an external consultant. The assignment resulted from a former analytical study prepared for the client by the consultant firm where I am employed. The study reviewed the possibilities of developing a marketing strategy at the client's company. This study indicated that although the client was still a market leader in Hungary with many of its products and services, his position was heavily threatened and therefore there was an obvious need to develop a marketing strategy.

Having considered many other conditions, including immediate privatisation and reorganisation, the management of the company decided that it was not time yet for developing a marketing strategy. However, they supported the idea of developing a good marketing information system with the involvement of the employees of the company to create a basis for a future project and to strengthen the marketing aspects within the company.

So they accepted the idea that in increasing competition they could achieve a significant competitive advantage if they created an information base which they could rely on in making marketing decisions. It was interesting and therefore should be mentioned that the top managers supported the project better as they learnt that with the marketing information system they could set tasks more accurately for the marketing management for which the marketing management would be accountable. The marketing information system aimed at the collection, classification, analysis and evaluation of information related to marketing. We set the goal of providing accurate, up-to-date and fast information to the marketing decision makers. According to our views this is feasible if both the contents and the structure of the information system are consumer-oriented, competitor-oriented and reflect the service management concept.

It was clear already at the beginning that, similarly to marketing, a marketing information system can work well in an organisation only if it is not owned and used by a limited number of specialists but affects the everyday activities of the organisation. Naturally when the system is created and operated there is a need for a co-ordination team, but successful operation is subject to contributions from everybody who is involved in marketing. It is important that people should recognise that the information system is assisting them and that they can also promote its better operation. At the beginning of the development we stressed that the final result will be subject to the acceptance and involvement of the staff of the company. 


\section{IMPLEMENTATION}

\subsection{Where shall we begin?}

The development of a marketing information system requires several years of work. Although the assignment of external consultants included the formulation of the concept of the system and the implementation of some "pilot study" type sub-systems, for which we allocated 18 months, we always said that we should prepare for very intensive work estimated for around 10 years in the technical literature. Our ideas concerning the project are illustrated very well through the fact that the development schedule was suggested to the client on the basis of the scheme often referred to in relation to the development of decision support systems. The steps of the scheme are the following:

- Definition of main problems and opportunities

- Definition of decision making problems in these key areas

- Analysis of the decision making processes and decision making environment

- Definition of the principles of modelling and formation of the model base

- Data base design, collection of data

- Software development and analysis

- Development of a user interface

- User testing and supplements

- Implementation

In fact, the assignment covered the support of the first five steps only. Essentially this involved the system design and functional specifications as well as the specification of requirements for the system. The further steps are rather technical and we did not deal with them directly, although made several recommendations for the IT solutions as it was kept in mind all the time that the system will work on computers.

Having studied the activities of the company, it became clear that the decision making processes and even the organisational structure focused on product and service categories. This is why the decision was made that the marketing information system had to follow this structure and development had to take place in a way that the product and service categories could be integrated into the system one after the other.

First we selected a product category which was competing at an expansive market, was still a market leader but was heavily threatened by the competitors. If we put this product into the portfolio matrix of the Boston Consulting Group, it would clearly fall within the "star" category. The distribution of the product requires an IT background and thus we had accurate data and, since it was a relatively new product all the chronological data were also available. However, it turned out in the case of this first example that the company stored mainly turnover data and there was no consequent data collection about the consumers of the product or the competitors.

The above information could only be used to assess the current situation but it should be noted that only one function could be fully supported, namely external reporting. The company had to provide regular reports for the supervising authority to which it belongs according to its profile and also to the Statistical Office. Within the company, information management was over-centralised and concentrated on the current information demand, computer systems of different philosophies were mixed up, information was managed passively and there was a total lack of collection of marketing information. At the same time it was clear that the right information could be used much more effectively as well. The performance of the company could improve if it were able to use the information to prepare marketing answers through which it could strengthen its position in the market. 
For this purpose the marketing information system must provide at least three kinds of support.

Resource support, which takes place in the form of data bases and model bases. In our specific case this means the definition of the data base which contains the main features of the analysed product categories, the variables describing the consumers of the product category and the typical features of the competitors who are active at the market. The model base collects the methods with which data are manipulated, e.g. through frequency histograms, calculation of indices, simulations, etc. The format of standard reports must be defined there too.

- Process support which means the definition of the tasks which may be performed better using the information available through the system. In the case of a product category it is a justified requirement for the marketing information system that it should support the segmentation of the consumers purchasing the product category and, on the basis of the turnover data, it should indicate where new points of sales should be set up and ways in which the company could improve its position at the market.

- Intellectual support which involves supporting of creative ideas and principles as well as structuring the problems. An example for that could be the integration into the system of the results of public surveys about the product which may suggest how potential consumers could be approached. Better planning of cross-selling actions could also promote acquisition of customers. Thinking about competitors could be stimulated by showing their strengths and weaknesses through which a better competitive strategy could be formed.

Usually marketing decisions have three dimensions. They affect the consumers as they try to influence them, they relate to the competitors, as is reflected in the competitive strategy, and they relate to the company products, as the market position of a company can be improved a lot through the modification and development of its products. These opportunities, directions and marketing tools had to be explicitly included in the information system as well. These requirements impacted mainly as the specification of the contents of the information system, but were also taken into account when the structure of the system was planned.

In our case, the data and analyses related to the various product categories appeared in three segments. These were called modules. The three modules in fact represented consumerorientation, competitor-orientation and service management concept and this was also reflected in their titles: consumer analysis module, competitor analysis module and product analysis module. They may be summarised briefly as follows:

The consumer analysis module is the basis of the consumer-oriented marketing strategy. The objective of the strategy is to get better information about the consumers which is only possible by completing the transaction data, which are mainly related to turnover, with other information of the behaviour, motivations and satisfaction of consumers. Naturally, in order to capture this information, one must use different methods, e.g. enquiry, observation. In addition to individual customers, company customer should be given special attention and existing and potential customers should also be distinguished.

- In the competitor analysis module the data of competitors are collected, managed and analysed. We had to make it clear that provided that the company intended to keep its market leading position and the wide range of products, it could not exist without most accurate information concerning the activities of its competitors. Two types of competition were distinguished. We dealt with global competition among companies of 
similar profiles e.g. for funds and with product competition which may be observed in a specific segment of the market.

The information in the product analysis module is used to develop the products of the company and make their sale more successful. The most obvious marketing tool is improvement of the product and making it compatible with the market. Naturally the product analysis module consists of the sub-systems which represent the product categories of the company.

\subsection{Problem owners and problems in decision making}

After the concept of the system had been outlined, actual work began. Naturally the first task was to assess the currently used marketing information, the producers of that information and to define the users of the information. The first shock occurred when we learnt that more than one hundred information systems operated within the company in parallel with each other. It was no longer a surprise that they practically did not communicate with each other. We also came across not accounting type data, e.g. results of consumer enquiries, but awareness of those and their use were very limited. Consequently, the first achievement of the project was to identify the location and flow of information within the company.

The most difficult task was to identify the users. The mission of the internal and external specialists involved in the development could have been defined as trying to develop a system providing marketing information which can reduce the risks and stress involved in decision making and, as a result of the improved decisions, lead to better results. For this we had to find the future users as the information system must support their work in future.

As already stated, the structure of the company is product-oriented. Decisions are prepared in a decentralised manner, at the level of business categories, yet decision are made centrally. Decision making is based on the classic method of organisations with a hierarchy. The decision making levels are separated according to the volume of expenses resulting from the decision. It was then clear to the developers of the information system that the problem managers are the managers of the business categories and the top level decision makers sitting at the top of the hierarchy. However, since the products of the company are mainly services, which are sold to the customers directly, there was also a requirement that the system should also support the person who is negotiating with the customer and tries to sell the service and intends to convince the potential customer that his product was much better than that of the competitors.

Many people have addressed the problem many times that usually the decision makers are unable to specify the information they need for their decisions. Therefore developers of information systems must try to guess what their requirements are - and they fail most of the time. We also tried to achieve the impossible and asked the decision makers responsible for the "pilot study" about the types of marketing decisions they usually made and the information used for those decisions. Unfortunately, this interview took place at a very bad psychological moment as the managers had to report to the top management on the results of the product during the recent period on the same day. The managers responsible for the product were very frustrated as it became clear from the report that the company intended to change the strategy for the product and the former expansive strategy preferring the increase of volume had to be replaced with a strategy focusing more on costs. You might think that, for this reason, our questions caught them at the best possible time but in fact they had not been able to digest what they had heard at the meeting yet.

Our original intention was not an informal talk or an interview as in the given situation these methods would not even have worked. Instead we used the group work method and reduced the question to a list of decisions which were related to marketing and we even 
assisted them. We specified some typical decision making subjects in connection with marketing:

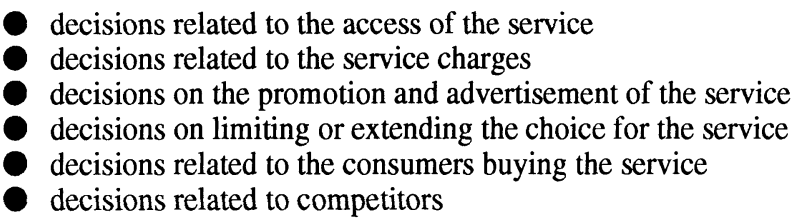

These unfortunate conditions were reflected in the quality of the answers. We had to get over it as it was more important to attract the attention of the problem owners and to get their support because our idea was that following the pilot study they would have to organise system management. This was only partly achieved. However, we also had more favourable experiences. In the product category, which was analysed next, we experienced much greater interest and intention for co-operation. Here managers actively assisted the work and the specialists worked continuously. It was also true that in this case the sales of the product had fallen drastically for the previous six months, mainly because of the significant reduction of purchasing power. As it was a product with lower costs but high sales revenues, the company wished to make it successful again, therefore the problem managers were committed to the objective.

As we were unable to specify all the user requirements for the system during the pilot study, we could only indirectly define the contents of the information system. Instead of the concept of a decision catalogue we introduced the concept of problem list which essentially meant a list of those subjects which covered the analytical areas and decision making dimensions, relevant for marketing. These were the following.

- The analysis of the users of the service involved the segmentation of consumers, analysis of the behaviour of customers and their satisfaction as well as identification of potential customers.

- In relation to the analysis of the access to service, we dealt with the functional and technical aspects of the service (in time, according to the form of service) and the current opportunities were compared to the customer requirements and expectations.

- In addition to simple turnover analysis, the analysis of the turnover of service extended to the definition of the priorities in sales, the impact analysis of the various sales promotion campaigns and the impacts of the changes in the service.

- The analysis of the market position of the service included the review of market tendencies, trends and participants, assumptions for the size of the market and market opportunities, a description of the economic environment, definition of the target groups, service positioning and market penetration.

- In relation to partners and competitors we collected the basic data which were available about them, all their known ideas, plans for possible co-operation and tried to identify the newcomers at the market.

- The analyses related to the quality of service were aimed at the foundation of a product policy within the marketing mix. Consequently, they extended to the review of the image of the product, product awareness, strategic importance of the product and its place in the portfolio, identification of the product objective and the processing of the history of the product within the company.

- The second element of marketing mix is the pricing policy, for the formulation of which the price flexibility of customers may need to be tested and some economic calculations may be needed. These analyses may clarify possible ways to increase profits. 
- The third element of marketing mix is the sales policy which cannot exist without a thorough analysis of the sales channels, processing of consumer requirements for the channels and an analysis of the complaints against sales.

- The fourth tool of marketing mix is the communications policy which includes the sales promotion campaigns, and marketing communications for which an impact analysis of indispensable. The information gained from those may be integrated into the planning processes of the future campaigns.

- A lot of stress was put on the integration into the marketing information system of the results of relevant research related to the given services and products. In this case we did not refer only to research ordered or carried out by the client, but to all relevant research results which were available.

- A separate subject was the technical background of services as the analysed products and services could only be sold successfully with high-level IT support. Naturally, the stress was placed on development opportunities.

- Finally, the list of the subjects was closed with interesting items which included information that was a special treat for the users either because it is absolutely up-to-date in nature or substance, or simply because it was simply striking.

\subsection{Logic of Information System Construction}

Our recommendations concerning the building and documentation of the system were derived from the final result. On the basis of the list of problems and modules we had a better understanding of what the marketing information system had to support. As much as we could, we identified the decision making personnel and analysed whether the various decisions were regular or individual decisions. The identification of the decision making points and situations aimed at the medium and top management through the identification of the problem situations which were relevant to them, but it also included some sales decisions, that is open issues for the lower decision making levels.

Then we had to concentrate on the outputs which had to be generated at the analysed decision making points of the information system. The definition of this information base was the result of lengthy discussions. The discussion focused on the extent to which users can be authorised to search in the data base individually and to which set of outputs should be included in the system. There was a demand for the "ready-made" outputs, but we were aware of the danger that the information generated this way would mainly reflect the ideas and interpretation of the developers and not those of the decision makers.

Therefore outputs were interpreted as the services of the information system. Their format also confirmed this as they were designed on screen. Each output had a single format. It included a graphic summary figure which was completed with a short explanatory text. The data forming the basis of the graph were mostly shown in tables which could be reached through the same, or a different screen. Thus all the information used was made available right through to the primary data. Stress was put on indicating the exact source of the data and we also showed the frequency of updates and the person responsible for them. The main objective was that the outputs should directly support decision making without further calculations or editing.

Following the design of outputs, the necessary analyses were described. By analysis we meant operations that transform the primary or aggregate data available in the information system into outputs. Naturally, one decision making point was connected with several outputs and the generation of one output also could require several analyses or the same analysis could support several outputs.

Following the compilation of the collection of analyses, the necessary data were identified. These data were either imported from different computer data bases or were out into the system as external data, that is they were not generated within the system. We had to 
make sure that the analyses should only use data the regular generation of which will be assured in future too. For example, in the case of information gained from public surveys this meant that in future these surveys will have to be repeated periodically. In case of uncertain subjects, such as a consumer survey aimed at the analysis of purchasing power, there may be a need to acquire data from several sources and confirm them. Within the company the collection of data should be put on a new basis and we recommended that the existing centralised method will soon have to be replaced with a different practice in which the relevant information is collected by the various business units who provide the information by entering it into the marketing information system.

At a general level Kotler and Armstrong define a marketing information system as consisting of: "people, equipment and procedures to gather, sort, analyze, evaluate and distribute needed, timely and accurate information to marketing decision makers." It is well known that managers ask for information not raw data, consequently we need analytic tools to provide the necessary information to them. Sometimes retrieval questions come up of course, but most often the answers to these questions require nontrivial manipulation of stored data. Knowing this told us much about the kind of support required and made it clear that a simple data base management is not enough.

We met a company who is the Hungarian distributor of EXPRESS the world wide used commercial system with a strong business orientation and were convinced that EXPRESS is appropriate for our purposes. This software offers an easy-to-use, Microsoft Windows interface and can perform competitive analysis, track product introductions and promotional effectiveness, conduct market-by-market comparisons, isolate trouble spots, adjust marketing and sales strategies. It integrates sales and marketing data from multiple internal and external sources which was very important for us, because our modules use mainly external data and provides a full range of ad hoc analysis and reporting tools. Ranking and exception-based reporting capabilities allow marketing professionals to quickly target, track, and analyse results using their own specified criteria. Links to popular spreadsheets and word processing packages facilitate the sharing of information and eliminate the need to reformat reports and allow the use of a gallery of graph types for investigating trends. Measure-creation tools allow the addition of new marketing calculations for more detailed analysis. Support for multiple hierarchies lets users organise data to suit their specific business needs and thus transform marketing data into business intelligence.

To illustrate all this, let us look at a specific example, though the company will still not be named. The example shows the work performed in the different modules. The example is taken from the pilot study and analyses the opportunities of sales promotion in relation to the analysed products. As we saw before, this product may not be sold without a computer background and turnover could be increased in different ways, either by increasing the number of transactions or increasing the turnover in each transaction. Both methods result in a bigger market share and reduce costs. The decision concerning sales promotion is made by the management of the business unit and decisions may be made once every six months or they may be occasional decisions, depending on the actions of competitors.

Many outputs support the decision. Let us now concentrate on the one which shows the monthly sales of the product to consumers according to various income categories. Naturally, primarily the spending habits of the company's own customers are interesting for active marketing but the review of similar data of competitors may also give useful additional information. In this case the output could be a pie diagram showing the consumer proportions according to the income categories. It could be supplemented with a background table in which the lines show the income categories according per capita monthly income and the columns show the sales of the company and competitors. Thus the table illustrates the spending habits, comparing them with the similar figures for the competitors.

To analyse this output we need to know the spending and saving habits of customers, as well as the tendencies for changing them. The data required for the analysis should include the income categories, the number of customers falling into those categories and the turnover figures. Such data may be collected mainly through personal enquiries as people are reluctant 
to give information about their income in any other forms, e.g. in writing. Naturally, the sales figures are available at the company. It is practical to assign a market research firm to collect the data, at least to complete the enquiries, or to ask those members of the staff who are in contact with customers even if not in relation to this product, but through other products. The information generated this way will only be reliable if it is updated at least once every six months, as in a turbulent economic environment the purchasing power of the population cannot be considered stable.

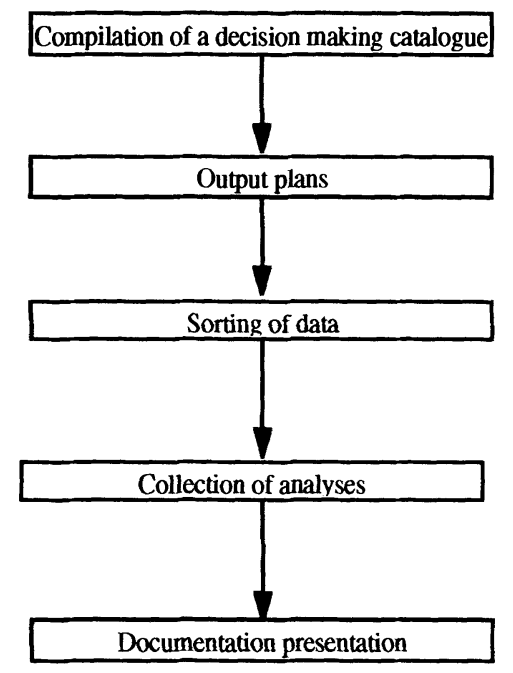

Figure 1 Scenario of the activities of the modules

How much does the shown output serve marketing? First of all it may indicate which of the customers of the company need more attention, and what should be concentrated on more: whether to increase the number of customers or to promote sales to existing customers. Targeted marketing campaigns may be prepared with it and thus the efficiency of marketing activities increases.

Figure 1 shows the algorithm for this work and the fact that development took place in practice at three levels. The first one could be called the planning or reconsideration level, characterised by assessments made by specialists. They covered different areas and summarised the dilemmas of experts. For example, this included the definition of parameters and features required for the decision making levels, the necessary but not quantified data for the decision concerning what should be stressed in the outputs for the various decision making levels. The issue of future operation of the information system, for which the developers intended to rely on the future users, also falls in this category. Experience shows thatpromoting the marketing information system itself requires serious marketing work before the users will agree to that task.

The second level involved the operation level where data are collected, verified and the data used in the analyses are generated. In fact data preparation and processing belong there. In the pilot study the main test of the operation level was loading data into the system from which we learnt a lesson, namely that many data could only be obtained with more difficulties than expected. This is mainly true for data related to the competitors and the internal expense figures of the company. It is natural that in the increasing competition the competitors protect the figures of their own operation and the expense figures were not 
available due to lack of controlling. However, it is promising that the controlling system is also being developed at the company and its level of completion makes it possible to pass on information to the marketing information system in the near future.

The third level of development is the user level. Convincing the users has always been a very important task. The system tried to provide them information classified according to dates, source and reliability and we continuously demanded feedback about the information put into the system and in relation to new requirements. The information system managed the user requirements in two dimensions. Information was generated for decision making levels and for special areas. We found that there was more interest in the latter group of information.

\section{ROLE OF THE MARKETING INFORMATION SYSTEM IN DECISION SUPPORT}

One of the most important successes of the assignment for the marketing information system was that those involved in the project understood the role of marketing, became aware of the importance of the market and that it was essential to share information about the market within the company. The information system was introduced to the organisation as a kind of collective memory and, although its development was suggested by the department responsible for marketing, we managed to involve representatives of other functions and business lines into the development.

The project organised for the development of the information system helped the participants to develop a new type of market-oriented thinking and provided a base of some classified information, though in specific areas only, which contains actual data about the given areas from marketing aspects. It is worth mentioning that, since marketing is an integrating function in the operation of the company, during the development we came across many strategic problems which do not strictly fall into the competence of developers. In such cases we did not go into the problems in depth but did not avoid them, either. Instead we tried to put into the information system further information assisting the marketing-oriented analysis of the analysed problems.

Data base marketing is becoming more popular in Hungary. In this case we chose a more tiresome way of marketing information system development, going beyond data base marketing, because we looked at system development as a learning process for the client company. The members participating in the project did not only represent their own organisational units but also acted as catalysers. They were creative, disclosed problems and requirements, collected and classified information and in the meantime they were thinking about the future of their company.

\section{REFERENCES}

Barabba, V.P. and Zaltman, G. (1991) Hearing the voice of the market: competitive advantage through creative use of market information. Harvard Business School Press, Boston.

Cats-Baril, W. and Huber, G.P. (1987) Decision Support Systems for Ill-Structured Problems: An Empirical Study. Decision Sciences, 18, 351-371.

Checkland, P. (1981) Systems Thinking, Systems Practice. John Wiley and Sons.

Dockerry, E. (1991) The strategic use of information systems technology in banking firms and building societies. Working Paper No. 117, City University, London.

Doll, W.J. (1985) Top Management Involvement in Successful MIS Development, MIS Quarterly, March, 17-35.

Douglass, D.D. (1990) Building Marketing Information Systems. I/S Analyzer, 28, 1-12. 
Er, M.C. (1988) Decision Support Systems: a summary, problems and future trends. Decision Support Systems, 4, 355-363.

Finlay, P.N. and Morteza, F. (1995) A Consultant Advisory System for Decision Support Systems, Research Series Paper 19, Loughborough University Business School.

Humphreys, P.C. and Berkeley, D. (1983) Problem Structuring Calculi and Levels of Knowledge Representation in Decision Making. in Decision Making under Uncertainty (ed. R.W. Scholz), North Holland, Amsterdam.

Humphreys, P.C. and Nappelbaum, E.L. (1995) Structure and communications in the process of organisational change: Eastern European experience and its general relevance. in Decision Support in Organisational Transformation (ed. B. Mayon-White, S. Ayestarán and P.C. Humphreys), Universidad del Pais Vasco, San Sebastian.

Kotler, P. and Armstrong, G. (1991) Principles of Marketing. Prentice-Hall, Englewood Cliffs, N. J.

Loebbecke, C.and Kronen, J.H. (1995) Fips sets the fashions: a DSS for purchase planning in a European department store. in Decision Support in Organisational Transformation (ed. B. Mayon-White, S. Ayestarán and P.C. Humphreys), Universidad del Pais Vasco, San Sebastian.

Meador, L.C., Guyote, M.J. and Keen, P.G.W. (1984) Setting Priorities for DSS Development. MIS Quarterly, June, 117-129.

Paprika, Z. and Zoltay, A. (1994) The Current Hungarian Business Climate. BEAMS Doc. UR-RR-006. Department of Business Economics, Budapest University of Economic Sciences.

Phillips, L.D. (1992) Gaining corporate commitment to change. in Executive information systems and decision support (ed. C. Holtham), Chapman and Hall, London.

Porter, M. (1980) Competitive Strategy. The Free Press, New York.

Sol, H.G. and Vecsenyi, J. (1990) Environments for Supporting Decision Processes. North Holland, Amsterdam.

\section{BIOGRAPHY}

Dr. Zita Zoltay Paprika is an assistant professor at the Business Economics Department of Budapest University of Economic Sciences. She teaches decision making theory and decision making methodology at undergraduate, graduate and post-graduate levels. She is in charge of the minor organised for graduate students which is called "Managerial Decision Making". She also permanently works as a consultant during which activity she has been a project manager on several occasions. From 1991 to 1994 she was the Hungarian co-ordinator of the TEMPUS BEAMS (Business Economics and Management Support) JEP-2360 Project financed by the European Union. At the moment she is the manager of the follow-up project of the same project. She is also the manager of the Decision Making Methodology Project of the Competitiveness Programme, which is organised by the Business Economics Department, and studies the competitiveness of the Hungarian micro-sector. 